\title{
Comparative efficacy of Eucalyptus (Citrodora) oil and xylene as dewaxing and clearing agents in hematoxylin and eosin staining procedure
}

\author{
S.P Akpulu ${ }^{1}$, W.O Hamman ${ }^{1}$, S.B Oladele ${ }^{2}$ and S.A Ahmed ${ }^{3}$ \\ Department of Human Anatomy, Ahmadu Bello University Zaria, Nigeria ${ }^{1}$ \\ Department of Veterinary Anatomy, Ahmadu Bello University Zaria, Nigeria ${ }^{2}$ \\ Department of Pathology, Ahmadu Bello University Teaching Hospital Zaria, Nigeria ${ }^{3}$
}

\begin{abstract}
Hematoxylin and eosin ( $\mathrm{H}$ and $\mathrm{E})$ staining of tissue sections is one of, if not the most widely used stain in routine histological or histopathology purposes. During Hand E staining procedure, dewaxing, the removal of paraffin in the tissues which is usually the first step to the staining procedure and clearing, the removal of dehadrant after staining before mounting plays a very important role during the microscopy. Xylene has often been used as dewaxing and clearing agents despite its associated hazards. Other xylene substitutes have been reported as clearing agents during tissue processing, with little or no emphasis on their efficacy during staining. The aim of this study is to compare the efficacy of eucalyptus (Citrodora oil), as dewaxing and clearing agents in hematoxylin and eosin staining procedure with a view of using it as possible substitute to xylene in $\mathrm{H}$ and $\mathrm{E}$ staining procedures. The study was carried out in the department of Human Anatomy ABU Zaria. The Citrodora oil was extracted in NARICT and analyzed in department of Pharmaceutical Sciences ABU Zaria. The study was carried out in the department of Human Anatomy ABU Zaria. Ten paraffin blocks of liver and kidney tissues each were retrieved from the department archives. Two sections from each of the blocks were made at 4 microns, and stained with Hand E. One from each of the two sections were all dewaxed and cleared in xylene while the other remaining sections were dewaxed and cleared in Citrodora oil respectively. The staining quality was evaluated by direct microscopic observation and graded. Results showed a similarity in the staining quality and no significant difference in the staining quality between tissues of the sections dewaxed and cleared in Citrodora oil and xylene. In cconclusion, Citrodora oil can be an effective dewaxing and clearing agents during Hand E staining procedure. It can be an alternative to xylene during $\mathrm{H}$ and $\mathrm{E}$ staining procedures.
\end{abstract}

Key words: Citrodora oil, xylene, dewaxing, clearing, staining

\section{INTRODUCTION}

Accurate diagnosis depend on producing quality microscopic sections and staining. Quality staining is highly dependent on processing steps. It is appreciated that the Hematoxylin and eosin (H\&E) stain form part of routine histological laboratory stain. One of the most critical steps in the Hand E staining is the dewaxing, which is the first step that removes paraffin from the tissue section surface to enable staining. Paraffin section is not mixable with water and Hand E stain is aqueous based, therefore the need to dewaxed (deparaffinazed) before the staining. After the staining, stained slides are usually air dry or dehydrated with alcohols before mounting with coverslips. Clearing of the tissue at this step do not only remove the dehydrant which in most cases is not mixable with the mountant, but also increases the refractive index of the tissues, leading to better visualization during microscopy. This is easier since the clearing agents is usually mixable with the dehydrating agents and the mountants.

Xylene $\left(\mathrm{C}_{6} \mathrm{H}_{4}(\mathrm{CH} 3)_{2}\right)$ is a chemical aromatic hydrocarbon [1] with an excellent tissue dewaxing and clearing capabilities and hence routinely used in staining of tissue sections [2] Xylene is used in the dewaxing of the tissue slides before taining and as clearing agents before cover slipping (mounting) [1]. Despite the remarkable utility of xylene in histological staining, there are reports that its use is associated with potential occupational hazards. It can cause debilitating effects on skin, eyes, nervous system, blood, liver and kidneys. Hence in the quest to eliminate or reduce the use of xylene in histology/histopathology laboratory, numerous substitute chemicals such as limonene reagents, aliphatic hydrocarbons, aromatic hydrocarbons, vegetable oils, olive oil and mineral oil substitutes were used in the past [1]. Most of these techniques is basically attempting to substitute xylene during the tissue processing with little or no emphasis on the staining techniques, which this study seek to address. Moreover, any technique, which can minimize or replace the use of xylene in histopathology laboratory, will be valuable not only for diagnostic reasons but as well as for maintaining a relatively safe laboratory environment.[3]. Hence the present study aimed to compare the staining efficacy of Citrodora oil and xylene as dewaxing and clearing agents during Hand E staining with a view of using it as possible substitute to xylene in $\mathrm{H}$ and $\mathrm{E}$ staining procedures. Xylene exists in three isomeric forms namely ortho- meta- and para-xylene [4]. 
DOI: $10.17148 / I A R J S E T .2021 .8423$<smiles>Cc1ccccc1C</smiles>

\section{1,2-dimethylbenzene} (xylene)ortho-

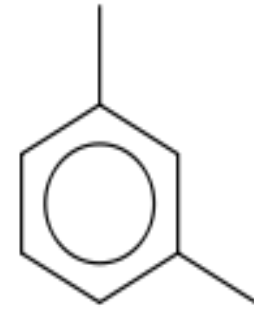

1,3-dimethylbenzene (xylene)meta-

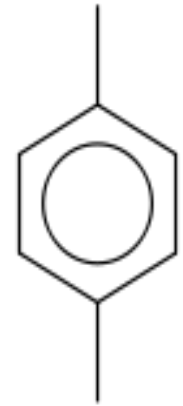

\section{1,4-dimethylbenzene} (xylene)para-

Fig: 1 Structural Isomers of Xylene. (Sourcs: Wikipedia, the free encyclopedia)

Eucalyptus (Citrodora) oil is the generic name for distilled oil from the leaf of Eucalyptus, a genus of the plant family Myrtaceae native to Australia and cultivated worldwide. It is also called Backhousia citriodora (B.citriodora) and used mainly for for medicine and flavouring [5]. Citrodora oil is a concentrated hydrophobic liquid containing volatile aroma compounds [6]. Citrodora oil has a clear, sharp, fresh and very distinctive smell, is pale yellow in color and watery in viscosity [7]. It has molecular weight of 154.25 and the structural formula of $\mathrm{C}_{10} \mathrm{H}_{18} 0$. The main chemical components of citrodora oil are a-pinene, b-pinene, a-phellandrene, 1,8-cineole, limonene, terpinen-4-ol, aromadendrene, epiglobulol, piperitone and globulol. It has a fresh camphor-like smell and a spicy, cooling taste. It is insoluble in water, but miscible with ether, ethanol and chloroform. The boiling point is $176{ }^{\circ} \mathrm{C}$ and the flash point is $49{ }^{\circ} \mathrm{C}$.The composition of the leaf oil is $90-95 \%$ citral, with some variable presence of citronellal, myrcene, methyl heptenone, linalol, and a- and bcyclocitrals [9].

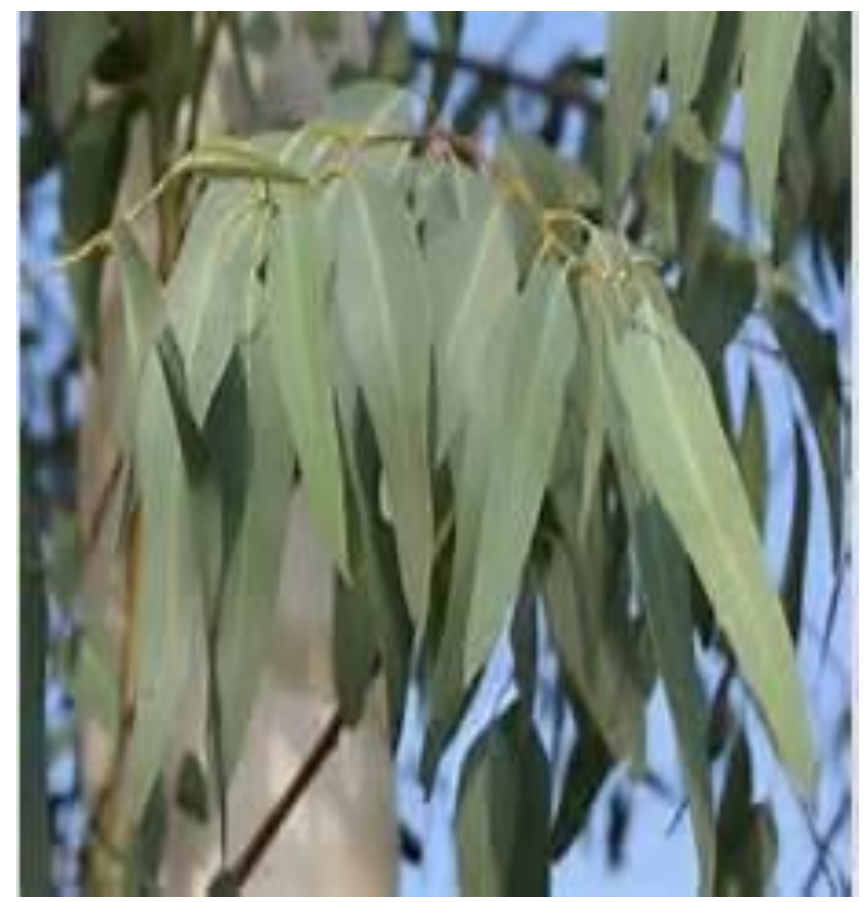

Fig. 2 Eucalyptus plant

(Source: Biological Technology Co. Ltd)

\section{MATERIALS AND METHODS}

The study was carried out in the department of human anatomy, Ahmadu Bello University, Zaria. Fresh leaves of Eucalyptus (Eucalyptus Citrodora Hook) plants were obtained from National Research Institute for Chemical Technology (NARICT) farm, Zaria, and the oil was extracted in NARICT by Hydro distillation using the method of Ladan, [10]. Ten paraffin blocks of liver and kidney tissues each were retrieved from the department archives. Two sections from each of the ten blocks were made at 4 microns using Rotary microtome (Leica RM2 125 RTS) made in England, and stained with Hand E. The two sections were separated into two sets. One set of the sections (labelled as X) were all dewaxed and cleared in xylene while the other remaining set of sections (labelled as C) were dewaxed and cleared in Citrodora oil respectively. The staining procedure is as outlined in table 1 below. Briefly; all the dewaxed 


\section{International Advanced Research Journal in Science, Engineering and Technology}

Vol. 8, Issue 4, April 2021

\section{DOI: 10.17148/IARJSET.2021.8423}

tissue sections were passed through descending grades of ethanol (absolute, 95\%, 90\%, 70\%) and rinsed in water. Hydrated sections were stained in Harris haematoxylin solution for 7 minutes and rinsed in water, differentiated in $1 \%$ acid alcohol. The sections were rinsed in water, blued in Scott ${ }^{\mathrm{s}}$ tap water briefly and the rinsed in water. The sections were counterstained in $1 \%$ eosin solution for 1 minute and rinsed in water. Each group of tissues section were cleared in Citrodora oil (group C) and xylene (group X) accordingly before mounted in DPX.

Table 1: The $\mathbf{H}$ and $\mathbf{E}$ staining protocol

\begin{tabular}{|c|c|c|c|}
\hline Procedure & Reagent & Time (Min) & Temperature $\left({ }^{\circ} \mathbf{C}\right)$ \\
\hline Dewaxing & Citrodora oil or xylene & 3 & 25 \\
\hline & Citrodora oil or xylene & 3 & 25 \\
\hline & Citrodora oil or xylene & 3 & 25 \\
\hline Rehydration & Ethanol 100\% & 3 & 25 \\
\hline & Ethanol 100\% & 3 & 25 \\
\hline & Ethanol 90\% & 3 & 25 \\
\hline & Ethanol 80\% & 3 & 25 \\
\hline & Ethanol 70\% & Not determined & 25 \\
\hline
\end{tabular}

The stained sections were examined microscopically (light microscope Olympus) and photomicrographed using the Amscope 3.0 digital camera for microscope and telescope made in China.

\subsection{Tissue Evaluation Criteria}

All tissue sections were coded and evaluated by independent Histo-Scientists who were blinded be the experiment. The criterial used for the assessment were the nuclear staining intensity, cytoplasmic clarity and contrast and and uniformity of stain. The staining quality were evaluated by direct microscopic observation and graded (scored). Each of the parameter were given a score of Excellent ( 5 scores), satisfactory (4 scores), Good (3 scores) fair ( 2 scores) or poor ( 1 score) respectively. The scoring criteria was modified from that employed by Marin [11].

\subsection{Statistical Analysis}

Data generated were analyzed using SPSS version 20. 0. Vales was expressed as mean plus or minus ( \pm ) standard error of mean (SEM). Chi-square test was used to check the association between type of clearing agents, and staining quality. $\mathrm{P}$-value less than or equal to $(\mathrm{P} \leq 0.05)$ was considered statistically significant.

\section{RESULTS}

Table 2: Comparison of efficacy Citrodora oil and xylene on the Staining Quality of Liver sections stained with $H$ and $E$

\begin{tabular}{|c|c|c|c|c|}
\hline \multicolumn{5}{|c|}{ Staining Quality of Liver } \\
\hline $\begin{array}{l}\text { Nuclear Staining } \\
\text { intensity }\end{array}$ & Citrodora Oil & Xylene & Total & Chi-square \\
\hline Fair & $0(0.0 \%)$ & $1(5.0 \%)$ & $1(5.0 \%)$ & $\mathrm{x}^{2}=4.485, \mathrm{df}=3, \mathrm{p}=0.214$ \\
\hline Good & $1(5.0 \%)$ & $1(5.0 \%)$ & $2(10.0 \%)$ & \\
\hline Satisfactory & $5(25.0 \%)$ & $1(5.0 \%)$ & $6(30.0 \%)$ & \\
\hline Excellent & $4(20.0 \%)$ & $7(35.0 \%)$ & $11(55.0 \%)$ & \\
\hline Total & $10(50.0 \%)$ & $10(50.0 \%)$ & $20(100.0 \%)$ & \\
\hline \multicolumn{3}{|c|}{ Cytoplasmic } & & Chi-square \\
\hline Contrast and clarity & Citrodora Oil & Xylene & Total & \\
\hline Fair & $1(5.0 \%)$ & $1(5.0 \%)$ & $2(10.0 \%)$ & $x^{2}=6.171, d f=3, p=0.104$ \\
\hline Good & $0(0.0 \%)$ & $1(5.0 \%)$ & $1(5.0 \%)$ & \\
\hline Satisfactory & $6(30.0 \%)$ & $1(5.0 \%)$ & $7(35.0 \%)$ & \\
\hline Excellent & $3(15.0 \%)$ & $7(35.0 \%)$ & $10(50.0 \%)$ & \\
\hline Total & $10(50.0 \%)$ & $10(50.0 \%)$ & $20(100.0 \%)$ & \\
\hline \multicolumn{2}{|c|}{ Staining Uniformity Citrodora Oil } & Xylene & Total & Chi-square \\
\hline
\end{tabular}


DOI: $10.17148 / I A R J S E T .2021 .8423$

\begin{tabular}{lllll}
\hline Fair & $0(0.0 \%)$ & $1(5.0 \%)$ & $1(5.0 \%)$ & $\mathrm{x}^{2}=6.171, \mathrm{df}=3, \mathrm{p}=0.104$ \\
Good & $1(5.0 \%)$ & $1(5.0 \%)$ & $2(10.0 \%)$ & \\
Satisfactory & $6(30.0 \%)$ & $1(5.0 \%)$ & $7(35.0 \%)$ & \\
Excellent & $3(15.0 \%)$ & $7(35.0 \%)$ & $10(50.0 \%)$ & \\
Total & $10(50.0 \%)$ & $10(50.0 \%)$ & $20(100.0 \%)$ & \\
\hline
\end{tabular}

Table 1: shows the comparison of type of clearing agents and staining quality like nuclear staining intensity (NSI), Cytoplasmic contrast and clarity (CCC) and staining uniformity (SIU) in liver sections stained with $\mathrm{H}$ and $\mathrm{E}$ using Chisquare test to check the association. From the result, there was no significant association between type of clearing agents and staining quality $(\mathrm{p}>0.05)$.

Table 3: Comparison of efficacy Citrodora oil and xylene on the Staining Quality of kidney sections stained with $\mathbf{H}$ and $\mathbf{E}$

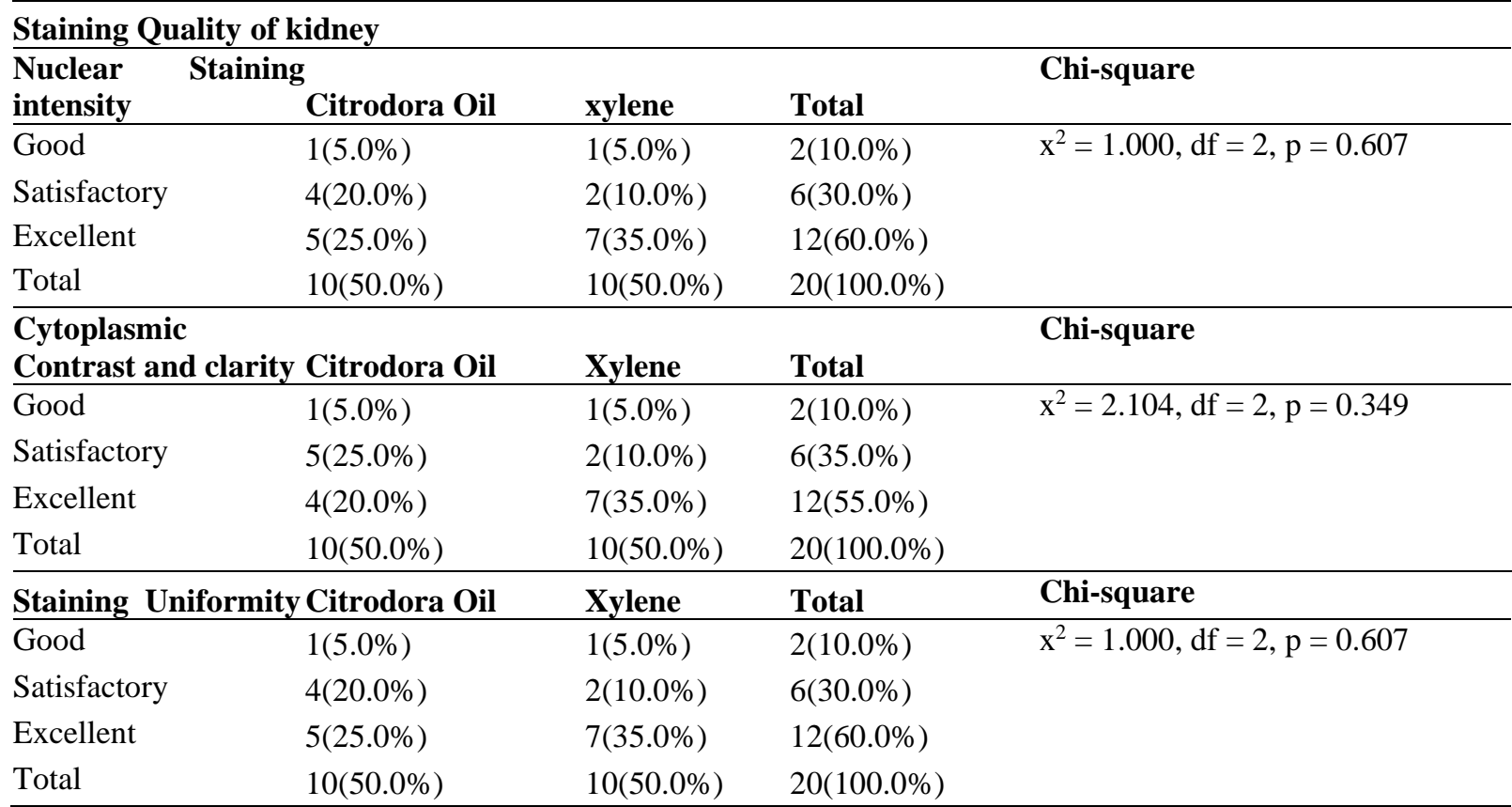

Table 3: shows the comparison of type of clearing agents and staining quality like nuclear staining (NS), Cytoplasmic contrast and clarity (CCC) and staining intensity and uniformity (SIU) in kidney sections stained with $\mathrm{H}$ and $\mathrm{E}$ using Chisquare test to check the association. From the result, there was no significant association between type of clearing agents and staining quality $(\mathrm{p}>0.05)$.

\subsection{Photomicrographs of stained Tissues}

The photomicrograph of kidney and liver sections of Wistar rats stained with Hand E are as presented below in plate I and plate II

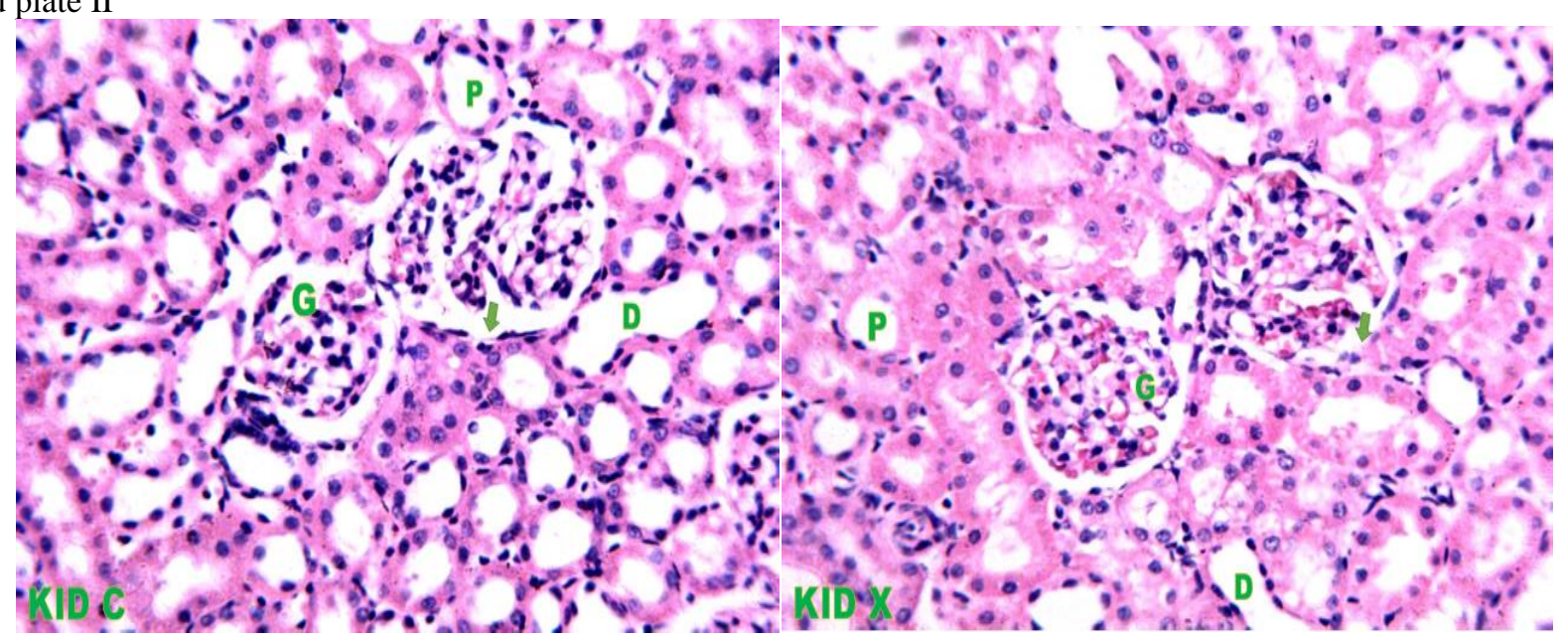


DOI: $10.17148 /$ IARJSET.2021.8423

Plate I: Renal sections dewaxed and cleared in Citrodora oil (KID C) and Xylene (KID X). The renal cortex shows Malpighian renal corpuscle containing glomerulus (G) and Bowman's space (arrowhead) present normal histological features. The proximal convoluted tubules $(\mathrm{P})$ and the distal tubules $(\mathrm{D})$ presented apparently normal cuboidal cells. The nuclear staining intensity, cytoplasmic contrast and staining uniformity appeared to be similar in both the KID C and KID X. H\&E x 250

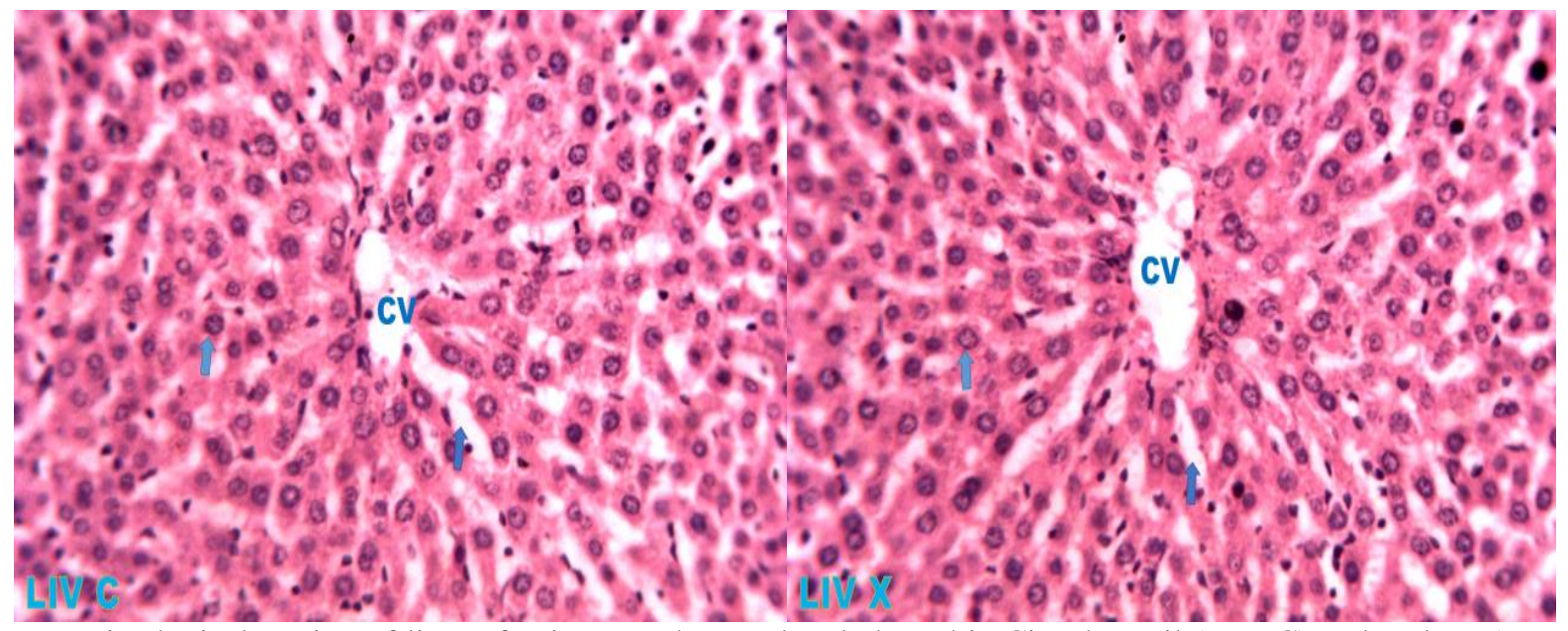

Plate II: Histological section of liver of Wistar rat dewaxed and cleared in Citrodora oil (KID C) and Xylene (KID X) during Hand E staining procedure. The section shows normal histological features with the central vein (CV), sinusoids (blue arrow) and the hepatocytes (blue arrow) appearing normal. The nuclear staining intensity, cytoplasmic contrast and staining uniformity appeared to be similar in both the KID C and KID X. H\&E x250

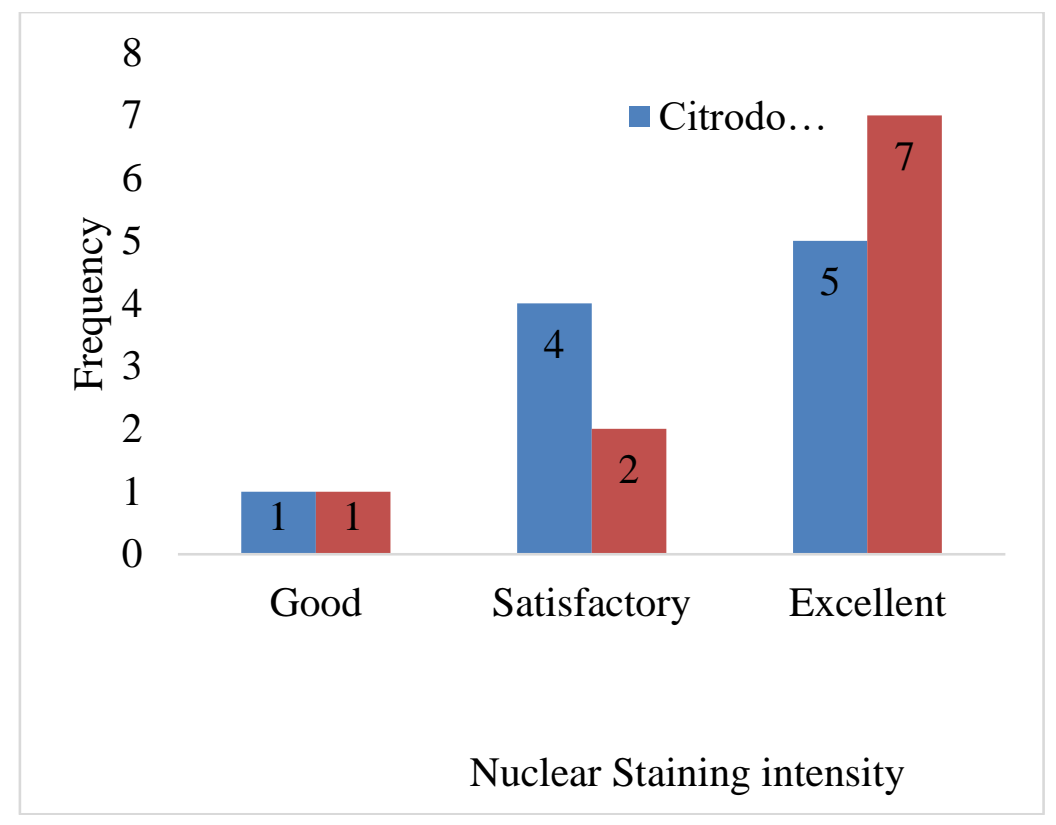

Fig. 3 Graph of showing the nuclear staining intensity of the kidney section stained with Hand $E$ after the dewaxing and clearing in Citrodora oil and xylene 
International Advanced Research Journal in Science, Engineering and Technology

Vol. 8, Issue 4, April 2021

DOI: $10.17148 / I A R J S E T .2021 .8423$

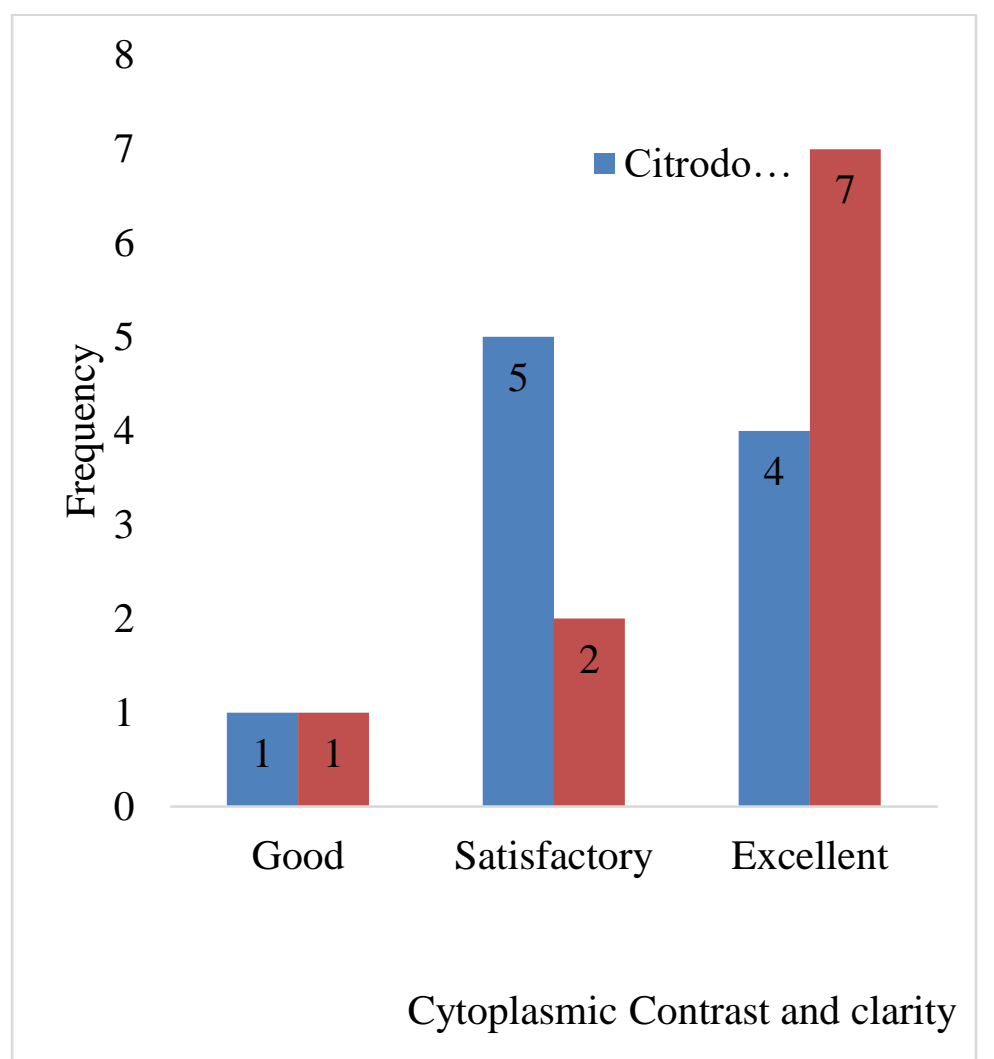

Fig. 4 Graph of showing the cytoplasmic contrast and clarity of the kidney section stained with Hand $E$ after the dewaxing and clearing in Citrodora oil and xylene

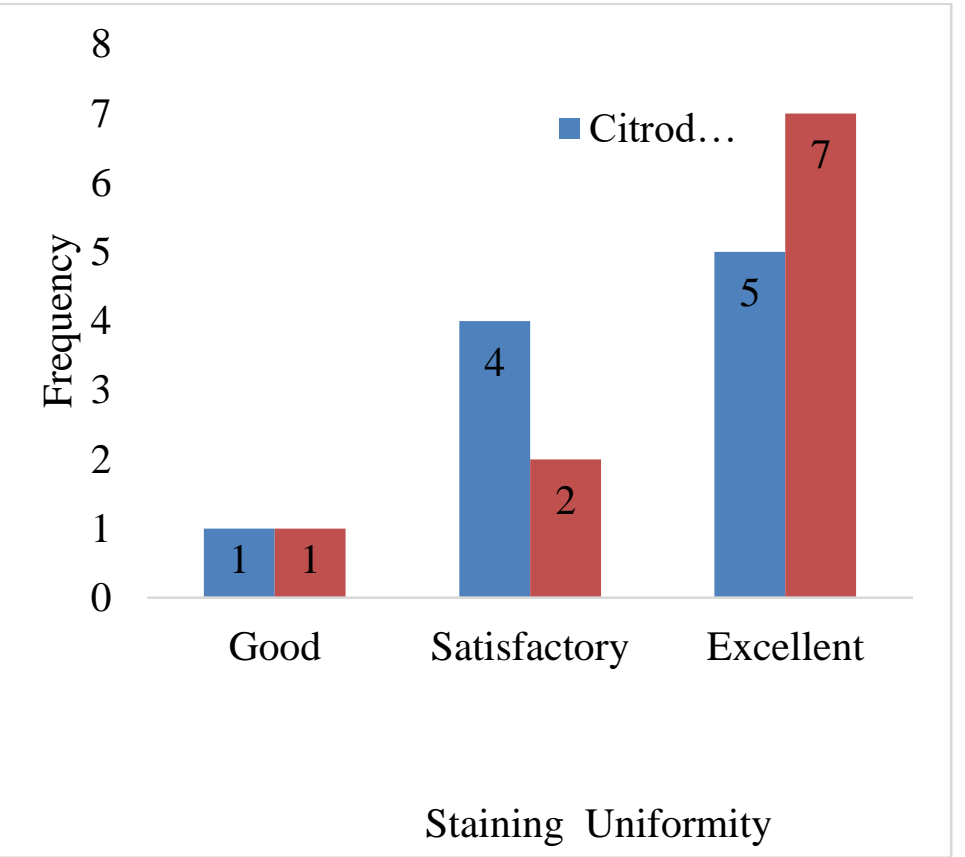

Fig. 5 Graph of showing the nuclear staining uniformity of the kidney section stained with Hand $\mathrm{E}$ after the dewaxing and clearing in Citrodora oil and xylene 
International Advanced Research Journal in Science, Engineering and Technology

Vol. 8, Issue 4, April 2021

DOI: $10.17148 /$ IARJSET.2021.8423

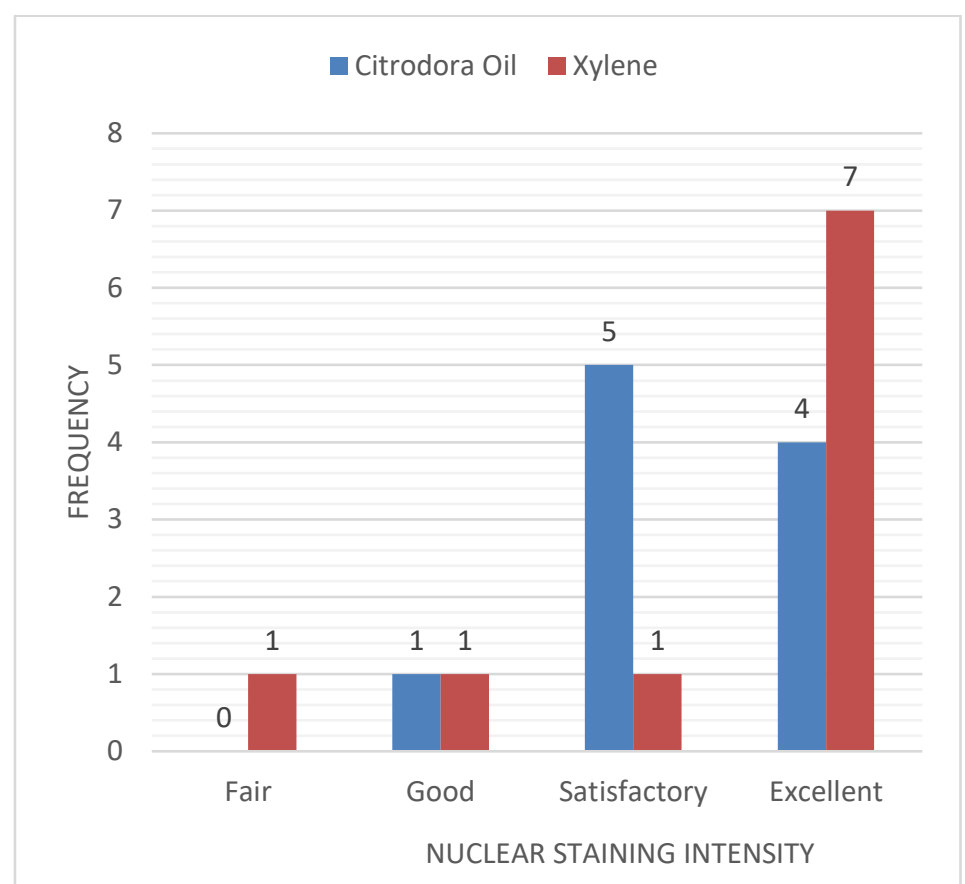

Fig. 6 Graph of showing the nuclear staining intensity of the liver section stained with Hand $E$ after the dewaxing and clearing in Citrodora oil and xylene

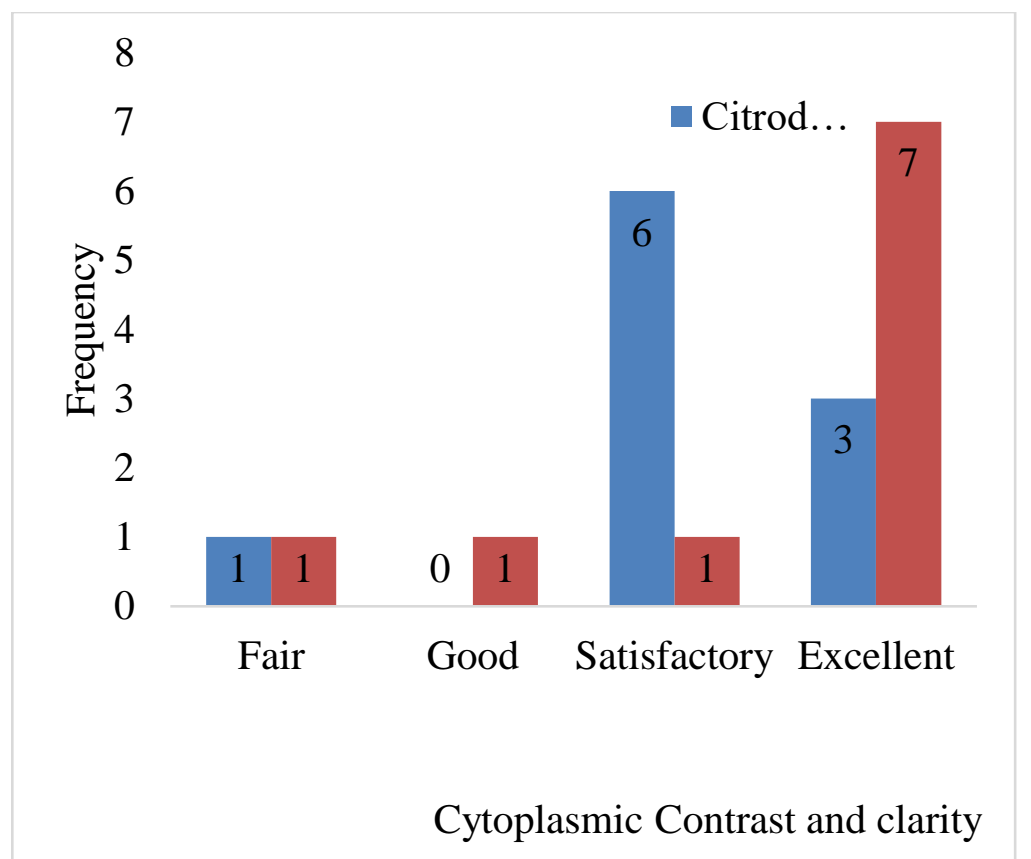

Fig. 7 Graph of showing the cytoplasmic contrast and clarity of the liver section stained with Hand $E$ after the dewaxing and clearing in Citrodora oil and xylene 
DOI: $10.17148 / I A R J S E T .2021 .8423$

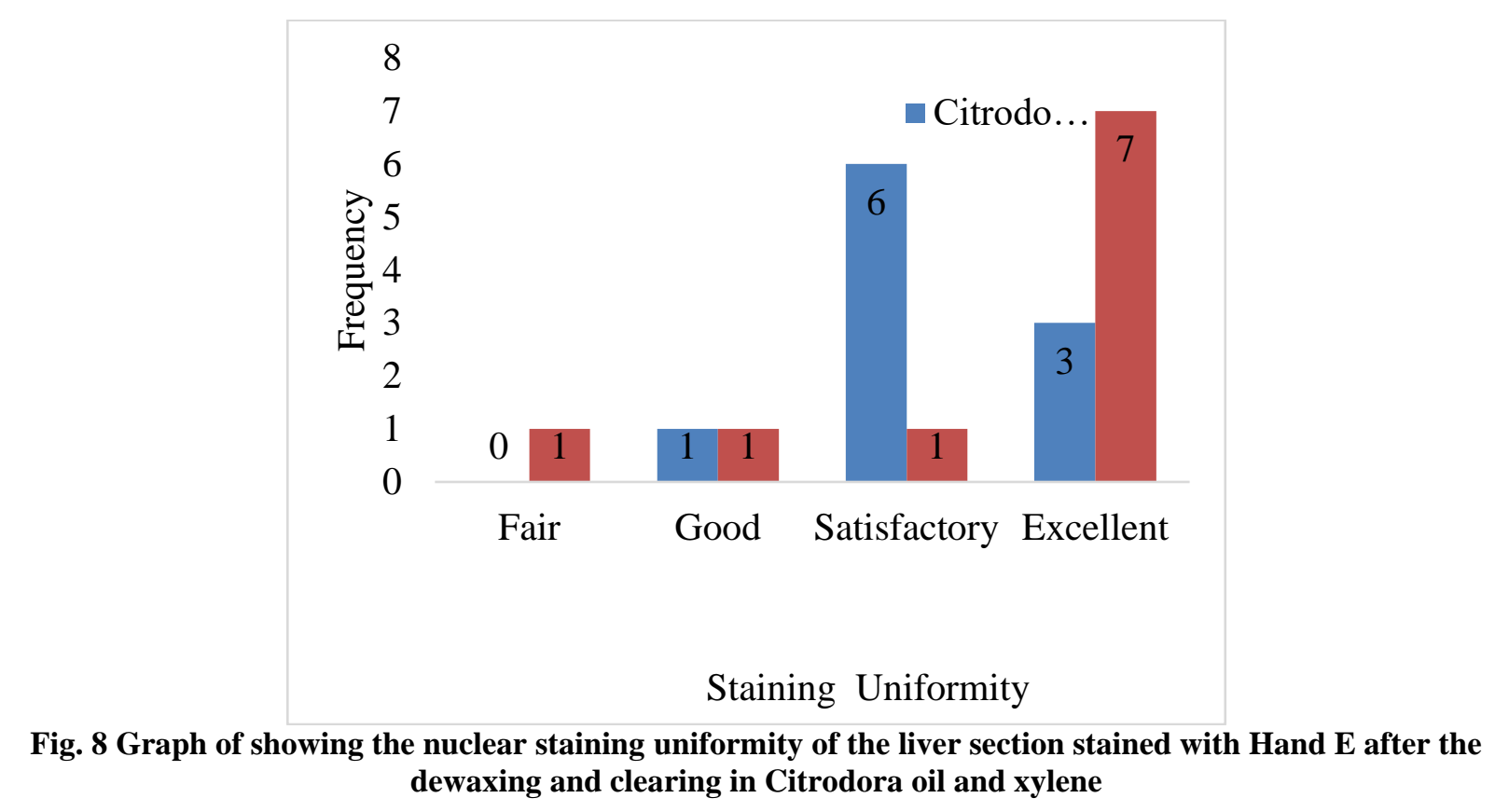

\section{DISCUSSION}

Since time memorial xylene has been one of the most widely used reagent in the histology/histopathology laboratories, especially in the tissue processing and staining techniques because of its excellent clearing and dewaxing properties. However, recently, reports has associated laboratory toxicity to xylene [1]. This has led to search for xylene substitutes as tissue clearing and dewaxing agents. Mixture of vegetable oils such as groundnut oil, palm kernel oil and coconut oil either alone or in combination with other clearing agents [12] has been reported to clear tissues. Orange based oil as clearing agents has also been reported by Rene [13]. Some essential oil such as olive, clove, coconut oil and cedal wood oil has been reported [14]. However, most of these commercially available xylene alternatives are less effective, more expensive, and are not as readily available as xylene [15]. To the best of our knowledge, there is little or no report of work on the comparing the efficacy of the staining ability of tissues dewaxed and cleared in Citrodora oil as xylene during Hand E staining procedure. Most of these commercially available xylene substitutes are less effective, more expensive, not readily available and are constitute health hazard as or more than xylene itself [16].

The finding in this study shows similarity in the staining quality of liver and kidney tissues of Wistar rats dewaxed and cleared with Citrodora oil and xylene in Hand E staining procedure. There was no significant difference in terms of the nuclear staining intensity, cytoplasmic contrast and staining uniformity. Plate I, represented the photomicrographs of the renal sections showing the glomerulus and Bowman's space presenting normal histological features. The proximal convoluted tubules and the distal tubules also presented apparently normal cuboidal cells. The nuclear staining intensity, cytoplasmic contrast and staining uniformity of the kidney sections dewaxed and cleared in the Citrodora oil appeared to be similar in the grading to that of the kidney sections dewaxed and cleared in the xylene. Similarly, plate II shows the sections of liver of Wistar rat dewaxed and cleared in Citrodora oil and Xylene during Hand E staining procedure, showing normal histological features with the central vein, sinusoids and the hepatocytes appearing normal. The nuclear staining intensity, cytoplasmic contrast and staining uniformity of the liver sections dewaxed and cleared in the Citrodora oil appeared to be similar in scoring as that of the kidney sections dewaxed and cleared in the xylene. The graphical representation shows varying report of the kidney and liver tissues sections to satisfactory or excellent as graded by the independent observers. However, the data analysis show no significant difference between the kidney and liver sections dewaxed and cleared in Citrodora oil and xylene during the $\mathrm{H}$ and $\mathrm{E}$ staining. In this study, we were not able to explain the full mechanism for these similarity observed, but it may be related to the higher refractive indices as reported by Akpulu [21]. Most of the work on essential oils as clearing agents is in agreement with this finding. Importantly essential oils are non-toxic, non-biohazardous and eco-friendly [17]. There are several reports on the use of cedarwood oil and lemon oil as clearing agents [20]. However, research trials using these solutions in tissue processing, have reported mixed results, and the emphasis has always been on the tissue processing with little or explanation on the staining procedures. It was observed [3] that there was significant correlation between cedarwood oil and xylene in terms of the three staining quality parameters assessed. They concluded that cedarwood oil can be an effective, eco-friendly and safe alternative to xylene as a clearing agent in the histopathological laboratory.

The present findings also agreed with the previous reports where cedarwood oil has shown to be a better clearing agent over xylene in tissue processing [18]. The major advantage of this Citrodora oil as dewaxing and clearing agents is that it causes almost no damage to the tissue, it is naturally extracted with no additives. Using Citrodora oil during Hand $\mathrm{E}$ 


\section{International Advanced Research Journal in Science, Engineering and Technology}

Vol. 8, Issue 4, April 2021

\section{DOI: $10.17148 /$ IARJSET.2021.8423}

staining procedures can give some health benefit, having been used in aromatherapy [17]. Another advantage of the Citrodora oil is that it takes the same duration as xylene to dewax and clear tissues. Although other clearing, agents like vegetable oils, mineral oils and home use dish washing soap water solution as a replacement for xylene in clearing of tissue sections has shown some promise, its potential effects on some tissue structure is a concern [19].

\section{CONCLUSION}

The present study shows that dewaxing and clearing in $\mathrm{H}$ and $\mathrm{E}$ staining procedure carried out using an Citrodora oil produced quality staining with sufficient clarity and uniformity of staining like xylene. It also has added advantages of being non-toxic, non-inflammable and non-hazardous and is easy to handle.

\section{RECOMMENDATIONS}

There should be more studies on using advance techniques such as immunohistochemistry, Molecular and enzymatic study, Fluorescence and electron microscopy of the effects of this Citrodora oil on tissues in tissue clearing and dewaxing techniques.

\section{ACKNOWLEDGMENT}

The authors sincerely thanked the National Institute for Chemical Research Technology (NARICT), Zaria and their staff for the extraction of the oil, and also the department of human anatomy, Ahmadu Bello University, Zaria for the enabling environment to carry out this work.

Source of Support: Nil.

Conflict of Interest: None declared.

\section{REFERENCES}

[1]. Kandyala R, Raghavendra SP, Rajasekharan ST. Xylene: An overview of its health hazards and preventive measures. J Oral Maxillofac Pathol. 2010;14:1-5.

[2]. Falkeholm L, Grant CA, Magnusson A, Möller E. Xylene-free method for histological preparation: A multicentre evaluation. Lab Invest. 2001:81:1213-21.

[3]. Indu S, Ramesh V, Indu PC, Prashad KV, Premalatha B, Ramadoss K.(2014). Comparative efficacy of cedarwood oil and xylene in hematoxylin and eosin staining procedures: An experimental study. Journal of Natural Science, Biology and Medicine 5:284-7.

[4]. Fabri, J., Graeser, U. and Simo, TA. (2002). Xylenes, Ullmann's Encyclopedia of Industrial Chemistry, Wiley-VCH, Weinheim. Pp 345

[5]. Seenivasan, Manickkam and Savarimuthu (2006). "In vitro antibacterial activity of some plant essential oils". BMC Complementary and Alternative Medicine, 6: 39

[6]. Pino, J.M., Sanchez, R. and Sanchez, E.R. (2006). "Chemical composition of orange oil concentrates". Nahrung / Food, 36 (6): $539-542$.

[7]. Julia, L. (1995). The Illustrated Encyclopedia of Essential Oils: The Complete Guide to the Use of Oils in Aromatherapy and Herbalism. Element Books Ltd.; Reissue edition. Pp 256

[8]. Jones, J.L. (1986). Ornamental Rainforest Plants of Australia, Reed Books, Pp.230-236

[9]. Doran, J.C., Brophy, J.J., Lassak, E.V. and House, A.P.N. (2001). "Backhousia citriodora, 16:325-328

[10]. Ladan, Z., Amupitan, J.O., Oyewale, O.A., Okonkwo, E.M., Ladan, E.O., Odjobo, B. And Habila, N. (2011). Chemical Composition and Biological Activities of the Volatile Oils of Hyptis Specigera against Trypanosome brucei brucei, (Tbb) Found In Northern Nigeria. African Journal of Pure and Applied Chemistry, 105(4): 53-58.

[11]. Marin-Palomo, P., Kemal, J.N., Karpov, M., Kordts' A., Pfeifle,J., Pfeiffer,M.H.P., Trocha' P.,Wolf,S., Brasch, V., Anderson' M.H., Rosenberger,R., Vijayan,K., Freude,W., Kippenberg,T.J., Christian Koos,C. (2017).Microresonator-based solitons for massively parallel coherent optical communications. Nature, 546, 274-279

[12]. Adeniyi M.I.,Adejoba O.R., Akinlabi F.M., Alao O.J. (2016). Vegetable Oils as Clearing Agents. Achievements in the Life Sciences, 10:1-4

[13]. Rene, J.B. (2000). Mineral oil: the best xylene substitute. The Journal of Histotechnology, 3(2).

[14]. Hans, L., Inger, H., Poul, P. and Eva, B. (1995). Non-hazardous organic solvents in the paraffin embedding technique: A rational approach.Histochemistry, 103:260-269.

[15]. Luna, L.G., (1992). Manual of histologic staining methods of the Armed Forces Institute of Pathology. McGraw-Hill, New York. Pp. 123

[16]. Udonkang M, Eluwa M, Ekanem TB, Asuquo OR, Akpantah AO (2014). Bleached palm oil as substitute for xylene in histology. Journal of Physics and Chemistry of Solids, 8(1): 8-17.

[17]. Spencer LT, Bancroft JD. Tissue processing. In: Bancroft JD, Gamble M, editors. Theory and Practice of Histological Techniques. 6th ed. Ch. 6. New York: Churchill-Livingstone; 2008. p. 86.

[18]. Morgan M. (2000). An observation-Cedarwood oil versus xylene as a clearing agent. Micscape Magazine Article. p. 62.

[19]. Ankle, M.R. and Joshi, P.S. (2011). A study to evaluate the efficacy of xylene-free hematoxylin and eosin staining procedure as compared to the conventional hematoxylin and eosin staining: An experimental study. Journal of Oral Maxillofacial Pathology., 15:161-7.

[20]. Spencer LT, Bancroft JD. Tissue processing. In: Bancroft JD, Gamble M, editors. Theory and Practice of Histological Techniques. 6 th ed., Ch. 6. New York: Churchill-Livingstone; 2008. p. 86.

[21]. Akpulu, S.P., Hambolu J.O., Ibegbu A.O. (2015). Evaluation of Some Essential Oils as Clearing Agents on the Histology of Some Selected Organs of Adult Wistar Rats. A Research Thesis Submitted to the School of Post Graduate Studies, Ahmadu Bello University, Zaria, Nigeria, Pp 4-57. 